\title{
Change, mechanism, and response of pollutant discharge pattern resulting from manufacturing industrial transfer: A case study of the Pan-Yangtze River Delta, China
} DOI:

10.1016/j.jclepro.2019.118587

\section{Document Version \\ Accepted author manuscript}

Link to publication record in Manchester Research Explorer

Citation for published version (APA):

Zhao, H., Liu, Y., Lindley, S., Meng, F., \& Niu, M. (2020). Change, mechanism, and response of pollutant discharge pattern resulting from manufacturing industrial transfer: A case study of the Pan-Yangtze River Delta, China. Journal of Cleaner Production, 244(118587). https://doi.org/10.1016/j.jclepro.2019.118587

\section{Published in:}

Journal of Cleaner Production

\section{Citing this paper}

Please note that where the full-text provided on Manchester Research Explorer is the Author Accepted Manuscript or Proof version this may differ from the final Published version. If citing, it is advised that you check and use the publisher's definitive version.

\section{General rights}

Copyright and moral rights for the publications made accessible in the Research Explorer are retained by the authors and/or other copyright owners and it is a condition of accessing publications that users recognise and abide by the legal requirements associated with these rights.

\section{Takedown policy}

If you believe that this document breaches copyright please refer to the University of Manchester's Takedown Procedures [http://man.ac.uk/04Y6Bo] or contact uml.scholarlycommunications@manchester.ac.uk providing relevant details, so we can investigate your claim.

\section{OPEN ACCESS}


Manuscript Number: JCLEPRO-D-18-11975R3

Title: Change, mechanism, and response of pollutant discharge pattern resulting from manufacturing industrial transfer: A case study of the Pan-Yangtze River Delta, China

Article Type: Original article

Keywords: Manufacturing industrial transfer; pollutant discharge pattern; driving mechanism; response relationship; PYRD

Corresponding Author: Ms. haixia zhao, Ph.D.

Corresponding Author's Institution: (1.Nanjing Institute of Geography and Limnology, Chinese Academy of Sciences

First Author: haixia zhao, Ph.D.

Order of Authors: haixia zhao, Ph.D.; Yan Liu; Sarah Lindley; Fei Meng; Mingjie $\mathrm{Niu}$

Abstract: Manufacturing industrial transfer is an important approach to promoting the optimisation and upgrading of industry, as well as leads to the spatial response of environmental pollution. In this paper, we applied the gravity centre model to measure the changes in pollutant discharge patterns from 2005 to 2015 in the Pan-Yangtze River Delta, and then investigated the drivers of pollutant discharge patterns changes with an improved econometric model which integrated the push-pull theory and STIRPAT random regression model. The results revealed great changes in pollutant discharge patterns due to manufacturing industrial transfer, with the pollution gravity centre and total discharge transferring from east to west. We also found indications of a delayed response between the movement of industry and a corresponding reduction in pollutant emissions. The modelling results suggested that differences in regional economy, technological innovation, industrial upgrading, and environmental regulation influenced observed changes in pollutant discharge patterns. Specifically, regional economic conditions and more stringent environmental regulations can push pollution-intensive industry out of developed areas into developing areas. Meanwhile improved innovation milieu and industrial optimization provided resistance for pollution-intensive industries to stay in developed areas as well as encouraging movement into developing areas. 
Dear Dr. Chen, Ph.D.,

Thank you very much for your letter, and the constructive comments and thoughtful suggestions about our paper (No. JCLEPRO-D-18-11975 Title: Change, Mechanism, and Response of Pollutant Discharge Pattern due to Manufacturing Industrial Transfer: A case study of the Pan-Yangtze River Delta, China). After carefully studying the comments and suggestions from the reviewers, we have checked and revised the relevant parts of manuscript. The main corrections in the paper and the responds to the comments are as following:

Responds to the reviewer's comments:

Reviewer \#2:

Comment 1: I suggest to improve the Introduction and Literature review.

Response: Thank you for your valuable advice. We have paid much attention to the relevant sections and reedited the manuscript. The introduction section has been rearranged to be better presented as well as more cohesive and logical. And in the literature section, we have made further explanation on the relevant contents and interpreted the existing studies as well as the correlation with our work in a clearer way.

\section{Reviewer \#4:}

Comment 1: In the Abstract section the synapsis "basic issues" could be replaced by a more specific one. This section could also be shorter, including the most important information regarding the work presented.

Response: Thanks for the instructive suggestions. We have made careful modifications on the Abstract section. The issues to be studied and the most important actions and results have been stated more clearly. As suggested by the reviewer, this section is also shorter now.

Comment 2: In the Literature Review section concepts terms such as 'pollution haven' hypothesis and theory of comparative advantages", since have been used as introductory terms, could be further elaborated in terms of the context of the specific research- in this section they are mentioned, however no explanation is provided in relation to the presented work.

Response: Thanks for the thoughtful suggestions. We have rewritten this section and made further elaboration on these concepts terms to explain the relation to our work, meanwhile the relevant researches were also provided to support. We explained the concepts and expect to theoretically support our research.

Comment 3: The section "Analysing response of pollutant discharge pattern to industrial transfer" is quite short; a brief description of the pollutant industry categories could be provided as well as their connection with this work. 
Response: Many thanks to your advice. We have revised this section cautiously and further described the pollutant industries to better present the content as well as their connection with our work.

Comment 4: It is not clear what is the connection of the 'Push and Pull" Theory Framework to the evolution of this work, so elaboration towards this direction could help.

Response: We are sorry for not addressing the part clearly. We have rewritten this part to elaborate the theory more clearly, and the interpretation of its connection with our research has also been added, according to your good advice.

Comment 5: The method applied is a good idea to be presented in a more clear manner as well as the motivation for choosing this method/approach over others. Some elaboration on why have the authors selected the IPAT Model for their work would help.

Response: Many thanks to your suggestions. We have revised the presentation of methods applied to improve this part. Furthermore, the motivations and reasons for choosing the specific model or method for our work have been explained in the revised version.

Comment 6: At some point of the paper, it would be a good idea authors to somehow inform the reader about the data and types of data that (s)he is going to read later on the paper so as to provide a holistic view.

Response: Thanks for your useful suggestions. According to your advice, we have added information about relevant data at some points of the manuscript to give readers a holistic view.

Comment 7: In the Discussion section authors need to provide in a more clear manner their findings and then make a comparison with existing literature so as to provide a clear scope of their produced work.

Response: Thanks for your valuable advice. We have revised this section to present it more clearly. We have tried to provide both our findings and its comparison with other existing studies, so as to clarify its contribution to existing literature as well as the aspects to be improved.

\section{Reviewer \# 5:}

Comment 1: This is the third time I have reviewed this paper and I don't have anything significant to add to previous comments. There are still one or two sentences/phrases that read rather clumsily but the meaning of the text can be understood so I would recommend publication on the basis that other reviewers are satisfied their comments have been actioned.

Response: Many thanks to your comments. We have revised the whole 
manuscript cautiously to make an improvement, and checked the English of the paper to avoid sentences difficult to understand.

Special thanks to you for your good comments.

If you have any question about this paper, please don't hesitate to contact us.

Yours sincerely,

Haixia Zhao,

Yan Liu,

Sarah Lindley,

Fei Meng,

Mingjie Niu 


\title{
Change, mechanism, and response of pollutant discharge pattern resulting from manufacturing industrial transfer: A case study of the Pan-Yangtze River Delta, China
}

\author{
Haixia Zhao ${ }^{1}$, Yan $\mathrm{Liu}^{2}$, Sarah Lindley ${ }^{3}$, Fei Meng ${ }^{1}$, Mingjie $\mathrm{Niu}^{1}$ \\ 1. Key Laboratory of Watershed Geographic Sciences, Nanjing Institute of Geography and Limnology, \\ Chinese Academy of Sciences, Nanjing 210008, China \\ 2. Jinan Environmental Research Academy, Jinan 250102, China \\ 3. School of Environment, Education and Development, The University of Manchester, Manchester \\ M13 9PL, United Kingdom
}

Correspondence information: Haixia Zhao, Nanjing Institute of Geography and Limnology, Chinese Academy of Sciences, Nanjing 210008, China,zhhx0183@163.com, +86 (0)25 86882132 
Highlights (for review)

\section{Highlights}

(1) We study change, mechanism, and response of pollutant discharge pattern in PYRD.

(2) Pollutant discharge patterns transfer from developed to developing areas.

(3) The pollutant discharge pattern shows spatial correlation with industrial transfer.

(4) Interregional differences drive pollutant discharge transfer. 
Change, mechanism, and response of pollutant discharge pattern resulting from manufacturing industrial transfer: A case study of the Pan-Yangtze River Delta, China

Haixia Zhao ${ }^{1 *}$, Yan Liu $^{2}$, Sarah Lindley ${ }^{3}$, Fei Meng ${ }^{1}$, Mingjie Niu ${ }^{1}$

1. Key Laboratory of Watershed Geographic Sciences, Nanjing Institute of Geography and Limnology,

5

Chinese Academy of Sciences, Nanjing 210008, China

2. Jinan Environmental Research Academy, Jinan 250102, China

3. School of Environment, Education and Development, The University of Manchester, Manchester

8 M13 9PL, United Kingdom

9 Abstract: Manufacturing industrial transfer is an important approach to promoting the

10 optimisation and upgrading of industry, as well as leads to the spatial response of environmental

11 pollution. In this paper, we applied the gravity centre model to measure the changes in pollutant

12 discharge patterns from 2005 to 2015 in the Pan-Yangtze River Delta, and then investigated the

13 drivers of pollutant discharge patterns changes with an improved econometric model which

14 integrated the push-pull theory and STIRPAT random regression model. The results revealed great

15 changes in pollutant discharge patterns due to manufacturing industrial transfer, with the pollution

16 gravity centre and total discharge transferring from east to west. We also found indications of a

17 delayed response between the movement of industry and a corresponding reduction in pollutant

18 emissions. The modelling results suggested that differences in regional economy, technological

"Corresponding author. Nanjing Institute of Geography \& Limnology, Chinese Academy of Sciences, 73 East Beijing Road, Nanjing, Jiangsu, 210008, China.

E-mail address: zhhx0183@163.com (H. Zhao), sarah.lindley@manchester.ac.uk (S. Lindley), 2515672599@qq.com (Y. Liu), mengfei1263@163.com (F. Meng), n1108mj@163.com (M. Niu). 
innovation, industrial upgrading, and environmental regulation influenced observed changes in pollutant discharge patterns. Specifically, regional economic conditions and more stringent environmental regulations can push pollution-intensive industry out of developed areas into developing areas. Meanwhile improved innovation milieu and industrial optimization provided resistance for pollution-intensive industries to stay in developed areas as well as encouraging movement into developing areas.

Keywords: Manufacturing industrial transfer; pollutant discharge pattern; driving mechanism; response relationship; PYRD

\section{Introduction}

With increasing economic globalization and worldwide environmental awareness, industrial transfer has become an important approach in promoting economic growth and industrial upgrading (Lu and Fan, 2012). It occurs under the influences of economic development, labour cost changes, regional policy discrepancies, and a variety of other factors (Xu et al., 2017). Besides, industries transferred are always sunset, or marginal, ones which lag technologically, or are characteristically human capital intensive, extensive energy and heavy pollution emitters (Yin et al., 2016), which can often lead to different degrees of pollution transfer and expansion. Under the general framework of global industrial transfer and neo-industrialization, China has increasingly attracted relocated manufacturing industries from developed economies due to the relatively loose environmental regulations, low production costs and other regional advantages (Dean et al., 2009). And the spatial transfer and agglomeration of manufacturing industries have resulted in associated environmental 
40 impacts, especially pollution transfer and diffusion (Guo et al., 2012). On the other hand, it has been documented that some areas with relatively strict regulations have not seen severe environmental degradation, even if pollution-intensive industries transferred to and concentrated in them (Yang et al., 2012; Zhao et al., 2015). This suggested that pollutant discharge may not always greatly change with the industrial transfer, for some reasons. Therefore, changes in pollutant discharge patterns as a result of manufacturing industrial transfer and its influencing factors need to be determined as the basis for regional environmental management improvement.

Aiming to determine whether, how, and why pollutant discharge patterns change during industrial transfer in China, this study focused on changing patterns of pollutant discharge and their determinants within the Pan-Yangtze River Delta (PYRD), China from 2005 to 2015. Applying multiple indicators, spatial analysis methods, and an econometric model, we investigated three interrelated research questions: (1) How has the pollutant discharge pattern changed? (2) How has this change responded to industrial transfer? (3) What factors have affected the changing patterns of pollutant discharge at a finer geographical scale? The revealed relationship between the distribution of industries and environmental pollution in response to industrial transfer can advance understanding of the restructuring process and mechanism of industrial transfer at finer geographical scales. Moreover, it can provide a theoretical basis for governing environmental pollution in the PYRD during the transformation period and has policy implications for interregional industrial transfer according to environmental constraints in newly industrialised regional economies. 


\section{Literature review}

The 'pollution haven' hypothesis and theory of comparative advantages have provided theoretical support for changes in the pollutant discharge pattern from industrial transfer (Candau and Dienesch, 2017; Millimet and Roy, 2015; Grether and Melo, 2003). They suggest that pollution-intensive industries tend to shift to areas with less stringent environmental regulations, emerging market, and lower production costs (Silajdzic and Mehic, 2017; Lian et al., 2016; Zhao et al., 2015), and as a consequence, the environment of these areas can be compromised (Zheng and Shi, 2017). Though there is still not a consensus on the pollution haven, with empirical studies in Turkey (Akbostanci et al., 2007), China (He and Wang, 2012), Latin American countries (Sapkota and Bastola, 2017), Sub-Saharan Africa (Kivyiro and Arminen, 2014) and so on, researchers have verified the phenomenon of pollution transfer in the process of international industrial movement, which had a negative impact on the environment and led to the changes in pollutant discharge pattern. Other studies also provided strong evidence for pollution haven hypothesis (Ederington et al., 2005; Zhang and Liang, 2010; Shahbaz et al., 2015). As for China, since the end of the twentieth century, eastern China and the Yangtze River Delta (YRD) in particular have undertaken international industrial transfer and become the destination for many pollution-intensive industries, such as chemical engineering, rubber, plastic, and textile industries, with massive quantities of pollutant discharge (Hou et al., 2013; Zeng, 2010). Subsequently, under the dual pressure of external markets and internal demand, pollution-intensive industries are frequently transferred from the eastern coast to the central and western regions in China (Liu et al., 2012; Zhao, 

2003). Dou et al. (2014) found that the pollutants such as waste water, $\mathrm{SO}_{2}$ tended to shift to the central region due to the transfer of pollution-intensive industries. Moreover, the destinations of industrial relocation in Jiangsu Province and the 'cage for a bird' policy in Guangzhou also bear the negative consequences of environmental degradation (Qiu et al., 2013; Shen et al., 2012). On the other hand, there can be advantages in terms of environmental quality in the context of industrial transfer, such as Germany's policy of domestic containment and international exportation through industrial upgrades during the middle of the twentieth century allowing an upward annual trend in domestic environmental quality. And Mielnik et al. (2002) pointed that foreign investment contributed to environmental improvement in destination areas for the introduction of advanced technology promoted the productivity and energy efficiency. Environment and pollution are usually related to industrial transfer, but the resultant environmental quality and pollutant discharge pattern may vary between different regions for a variety of reasons. Research on changing patterns of pollutant discharge in PYRD is expected to make practical significance for the regional development.

Previous studies have evaluated industrial and pollution transfer much, but were mostly been confined to isolated instances of industrial or pollution transfer and did not analyse their relationship and interaction (Zhao and Jiang, 2013; Zhao et al., 2014). And from a methodological perspective, they have followed similar research methods including descriptive analysis, evaluative analysis, clustering analysis, and spatial autocorrelation analysis (Li and Cao, 2013; Liang et al., 2012; Qiu et al., 2013; Wang and Shi, 2013). These 
methods tend to emphasize changes in spatio-temporal patterns in pollution or industries but reveal less about the internal mechanisms with which changes are associated. Zhang et al. (2011) analysed the decoupling between environmental pollution and economic growth and found the industrial structure has obvious effect on waste pollution. Wang et al. (2014) and Zhao and Jiang (2013) respectively elaborated the relationships between environmental pollution and economic development, direction of industrial transfer, and distance and path comparison. These studies have provided an important foundation for further research. Moreover, pollution transfer inevitably exists alongside the process of industrial transfer, but there is no final conclusion on which comes first. The transfer of pollutant discharge may come before that of manufacturing industries ( $\mathrm{Li}$ and Cao, 2013) or lag behind it (Gai et al., 2013). Research on the relationship between pollutant emission patterns and manufacturing industrial transfer still needs to be further explored.

The evolution of environmental pollutant discharge pattern is the result of multi-dimensional driving forces (Wu et al., 2019; Zhao, 2009). In previous studies, environmental regulation (Dam and Scholtens, 2008), environmental protection standards (Dong et al., 2012), and factor price were considered to be important factors influencing corporate production cost to promote industrial transfer. In addition, foreign investment (Cole and Elliott, 2003), international trade (Gao and Fan, 2009; Jungbluth et al., 2011; Muradian et al., 2002), technical advancement (Shi et al., 2012), and corporate responsibility factors were also major determinants of pollution-intensive industrial transfer leading to further changes in discharge patterns. While research in this area is active, it remains fragmented, and lacks a holistic 
124

125

approach (Shen et al., 2012; Wu et al., 2019), through which driving forces can be more rigorously examined and clarified. An econometric model can better indicate the degree of influence of each factor (Zhao, 2009), such as regression model, which is commonly applied for analysing the influencing factors with respect to data correlation. Lehmijoki and Rovenskaya (2010) and Moussiopoulos et al. (2004) discussed the influencing factors of atmospheric pollution transfer and analysed associated economic factors. But with evaluating the correlation among data given to obtain values reflecting the impact of human behaviour, this kind of model are therefore often overly dependent on data and could not provide a sufficient explanation of the mechanisms (Hoekstra and Van der Bergh, 2006; Hou et al., 2013; Xu and Zhang, 2009). Besides, the modified Todaro model and push-pull theory can analyse the driving effects of each factor in principle and their driving mechanisms, which has been discussed by Ye and Zhou (2008) and Wang and Shi (2013). However, only a few studies have analysed these concerns, and even fewer have done so quantitatively. It is therefore important to qualitatively as well as quantitatively determine the mechanism that drives pollutant discharge patterns during industrial transfer.

With the implementation of policies pertaining to industrial transformation and transfer of the YRD, as well as the rise of a central economy in China, the scope and strength of internal industrial transfer in the PYRD are intensifying. At present, industrial transfer is mainly characterised by the transfer of traditional manufacturing industries, such as nonferrous metal and non-metallic mineral production, mechanical equipment manufacturing, chemical engineering, food processing, and textile and garment industries, or partial production 
transfers from Shanghai, Zhejiang, and Jiangsu to northern Suzhou, western Zhejiang, and even Anhui and Jiangxi ( $\mathrm{Li}$ and Cao, 2013). Moreover, pollutant discharge patterns have changed (Zhao and Jiang, 2013). The emission loads of urban and industrial wastewater and gaseous emissions in Shanghai, Nanjing, and Hangzhou have been reduced, whereas those of Wuxi, Hefei, and other secondary cities have increased, showing a trend of pollution expanding from centre to the periphery of the country (Fan, 2004). However, the relationship between the response and internal mechanisms of the pollutant discharge patterns resulting from manufacturing industrial transfer has not been established, which is a motivation behind this research.

\section{Materials and methods}

\subsection{Study area}

This study was conducted in the PYRD, a region characterised by large gradient differences in regional development. The PYRD has been widely studied for its close regional links within the framework of regional division, cooperation, and integration with the YRD at its core (Zhu et al., 2010). Quantifying the economic attributes of the PYRD was first proposed by the Study on Cooperation Framework Agreement of the Pan-Yangtze River Delta in 2006. The spatial zoning of the PYRD is not currently unified, but there are four definitions in terms of scope: (1) ' $3+2$ ' mode, comprising Jiangsu, Zhejiang, and Shanghai, plus Anhui and Jiangxi; (2) '5 + 1' mode, comprising Jiangsu, Zhejiang, Anhui, Jiangxi, and Fujian, plus Shanghai; (3) '6 + 1' mode, namely Jiangsu, Zhejiang, Shanghai, Anhui, Jiangxi, and Fujian, plus Taiwan; and (4) ' $7+1$ ' mode, namely the areas under the ' $6+1$ ' mode and Shandong. In 
this study, the ' $3+2$ ' mode was adopted, and the location, sub-regions, and sample cities are presented in Fig. 1.

The PYRD is one of the most developed areas in China. It spans an area of $5.76 \times 10^{5} \mathrm{~km}^{2}$, accounting for approximately $6 \%$ of China's total area. By the end of 2015 , the total population in this region was $2.66 \times 10^{8}$, accounting for $19.4 \%$ of China's total population, with a gross domestic product (GDP) of USD $2.85 \times 10^{12}$, accounting for $26.1 \%$ of China's GDP. Driven by global industrial transfer, the PYRD will usher in a new turn in industrial restructuring and optimization, and industrial transfer is likely to expand considerably. In this context, the PYRD, with abundant labour resources, a mature market, and good industrial matching is suitable for an empirical study. This paper analyses the changes in pollutant discharge patterns and associated mechanisms in response to manufacturing industrial transfer in 2005-2015. Our investigation is based on industrial transfer processes and environmental pollution impacts which are considered to be typical for the study region.

\subsection{Method}

\subsubsection{Measuring changes in pollutant discharge pattern}

The regional gravity centre represents a certain point in the space of a regional economic society, and 'power' of certain attributes in each direction of the certain point can be kept in balance (Huang and Feng, 2006). It is usually applied to feature the spatial distribution characters of economic and environmental attributes (Ding and Li, 2009; Zhang et al., 2012), and provide a more quantitative way compared with other descriptive analysis methods. In 
186 this study, gravity centre method was adopted to calculate the geometric gravity centre of regional pollutant discharge, and its movement reflected the spatial changes of pollutant

188 discharge pattern. Attributes of economy and pollution in urban areas being not evenly 189 distributed makes the centroid of a city may not represent the gravity centre well (Zhao and 190 Jiang, 2013), thus the centre position of each province or city was set to its capital. It can be 191 calculated by Eq. (1):

192

$$
X=\frac{\sum_{i=1}^{n} X_{i} W_{i}}{\sum_{i=1}^{n} W_{i}}, Y=\frac{\sum_{i=1}^{n} Y_{i} W_{i}}{\sum_{i=1}^{n} W_{i}}
$$

193 where $X_{i}$ and $Y_{i}$ respectively indicate the coordinates of the longitude and latitude of the 194 capital of each province $i$, and $W_{i}$ indicates the generated wastewater, gaseous emissions, and 195 solid waste from 2005 to 2015 in the PYRD for province $i$.

196 Changes in the regional gravity centre can clearly reflect modifications in the trend of spatial 197 differences in changing pollutant emission patterns. Supposing that $d$ is the movement of the 198 centre of gravity in terms of distance from year $k$ to $k+1$, the specific equation is as follows:

$d_{(k+1)-k}=C \times \sqrt{\left(X_{k+1}-X_{k}\right)^{2}+\left(Y_{k+1}-Y_{k}\right)^{2}}$

200 where the constant $C$, equal to 111.111 , is a coefficient to convert geographic coordinates to 201 distances in kilometres, and $\left(\mathrm{X}_{k+1}-\mathrm{X}_{k}\right)$ and $\left(\mathrm{Y}_{k+1}-\mathrm{Y}_{k}\right)$ indicate the size of the change in the centre's coordinate from the year $k$ to $k+1$. 


\subsubsection{Analysing response of pollutant discharge pattern to industrial transfer}

\section{Pollution-intensive manufacturing industries usually have larger scale and higher pollutant} emission intensity, and if not controlled properly, can generate a significant amount of pollution, either directly or indirectly, during manufacturing processes (Wu et al., 2019). Besides, their spatial distribution and evolution are basically in line with the pollution discharge pattern (Zou et al., 2016). Therefore, pollution-intensive manufacturing industries were chosen to be studied in this research.

Adopting the pollutant industry categories provided in the National $1^{\text {st }}$ Pollution Source Survey Proposal issued by the Chinese State Council, 10 types of pollution-intensive industries were selected and shown in Table 1, including food manufacturing, textile, papermaking and paper products, chemical materials and chemical products, ferrous metal smelting and rolling processing, etc. Meanwhile, the fluctuations of polluting industries as well as the industrial transfer were characterized by changes in gross industrial output value, and the environment pollution patterns changes are represented by changes in pollutant discharge and gravity centre. Complemented by relevant statistical data of pollutant and economy, analysis on the spatio-temporal relationship between polluting industries and pollutant discharge will indicate a space-time response of the pollutant discharge pattern to manufacturing industrial transfer. 


\subsubsection{Mechanism of pollutant discharge pattern}

\subsubsection{Push-pull theory framework}

Push-pull theory is a basic theory usually applied on population migration research, and point that the migration is the result of the interaction of two forces: push force and pull force $(\mathrm{Xu}$ et al., 2013). Similarly, the phenomenon of pollution-intensive industrial transfer, which to some extent results in pollutant discharge pattern changes, can also be explained using the push-pull theory (Wang and Shi, 2013). Various factors will act on the industrial transferal as either push forces or pull forces, and then drive the pollutant discharge pattern change. Push-pull theory is supposed to provide theory support for the mechanism study of pollutant discharge pattern changes.

According to the theory, the spatial transfer of pollution-intensive industries is a result of the interaction between transfer-out impetus (F1) and transfer-out resistance (F2) in the transfer-out place as well as the transfer-in pull (F3) and transfer-in repulsive force (F4) in the transfer-in place. Enhanced environmental awareness, improved environmental standards, and the local government have been encouraging pollution-intensive industries to export, thus create the main driving force F1. However, F2, in the form of good locations with good facilities, strong technical research and development (R\&D) strength, and enormous sunk cost of enterprise and trans-regional labour flow, hinder industrial transfer. F3 includes low factor costs, poor environmental governance, large potential market, and strong investment possibilities by the government. However, F4 in the form of insufficient innovative ability, 
weak scientific R\&D capacity, poorly equipped industrial facilities, and poor investment environment at the transfer-in location hinders enterprises' transfer-in.

Based on syntagmatic relations among transfer-out impetus, transfer-out resistance, transfer-in pull, and transfer-in repulsive force, the driving model for industrial transfer from developed to developing areas was constructed (Fig. 2). The drive for industrial transfer (F power) refers to the combined force of F1 and F3. The resistance of industrial transfer (F resistance) refers to the combined force of F2 and F4. Only when the impetus is larger than the resistance can the industry be relocated from the transfer-out to the transfer-in place. For region III, the pull is strong and the repulsive force weak in the transfer-in place, and the impetus is strong and the resistance weak in the transfer-out place ( $\mathrm{F}$ impetus is larger than $\mathrm{F}$ resistance). The industry in the transfer-out location subsequently begins to transfer, and the transfer-in location begins to undertake the activity. Simultaneously, marginalised industries in the developed area will settle in the underdeveloped area. For Region I, the impetus is weak and the resistance strong in the transfer-out place, and the pull is weak and the resistance strong in the transfer-in place ( $\mathrm{F}$ impetus is smaller than $\mathrm{F}$ resistance). Under these circumstances, the power of industrial transfer in the transfer-out place is weakened, and as the circumstances at the transfer-in location are not advantageous, industries will not transfer out and will continue operating in the developed area. For region II, the pull is strong and the repulsive force weak in the transfer-in location, whereas the impetus is weak and the resistance strong in the transfer-out location. Finally, for Region IV, the pull is weak and the repulsive force strong in the transfer-in location, and the impetus is strong and the resistance weak in the transfer-out 
262 location. It is hard to determine the strength of F impetus and resistance, and the industry will therefore maintain the status quo and wait for suitable conditions before transferring. As the tendencies for transfer-out or -in have already been indicated for Regions II and IV, regional

265 industrial transfer will occur with an enhancement of the industrial driving forces.

$266 \quad 3.2 .3 .2$. Selection of factor index

267 Prior research has shown that the pollutant discharge pattern in the PYRD has changed

268 considerably over the past three decades (Li and Cao, 2013; Zhao and Jiang, 2013). This may

269 have been influenced by various factors, such as economic development, industrial structure,

270 technical effect, and government policy (Zhao and Jiang, 2013), represented by GDP per

271 capita, ratio of tertiary industry, environmental governance investment, utilisation rate of

272 industrial solid waste and so on. Considering the comprehensiveness of factor characteristics

273 and data availability, we selected several indicators from the perspective of four factors above

274 to analyse the driving mechanism of pollutant discharge pattern change, which are shown in 275 Table 2.

\subsubsection{Empirical model of driving mechanism}

277 When it comes to researches on driving factors of environmental change, the 'STIRPAT'

278 model, reformulated from the 'IPAT' model, has been widely utilized in existing studies (Shi,

279 2003; Wang and He, 2008; Liddle, 2013; Zhang et al., 2015). Overcoming the limitation that

280 IPAT model don't readily allow for non-monotonic or non-proportional effects, the STIRPAT 
282 the forces driving them (York et al., 2003), and has higher abilities on interpreting and analysing various driving factors. To better measure the impact and pressure of human activity on the environment, we adopted the STIRPAT model and made some modifications.

After considering the basic factors in the model and the regional features of the case study area in hand, we modified the model by adding typical influencing factors. The proportions of industrial wastewater discharge, gaseous emissions, and solid waste emissions in the national emission loads were used to balance the pollution transfer in the PYRD. Also, to eliminate the interference of heteroscedasticity on model estimation, the logarithmic model of pollutant discharge pattern evolution and influencing factors was established. The modified STIRPAT model is as follows:

$$
\begin{aligned}
& \ln Y_{i t}=\beta_{0}+\beta_{1} \ln R E G D P_{i t}+\beta_{2} \ln A W A G E_{i t}+\beta_{3} \ln U R B A N_{i t}+\beta_{4} \ln I S_{i t} \\
& +\beta_{5} \ln I C A_{i t}+\beta_{6} \ln D E A_{i t}+\beta_{7} \ln E G I_{i t}+\beta_{8} \ln G O V_{i t}+\varepsilon_{i t}
\end{aligned}
$$

where the explanatory variable $Y_{i t}$ refers to the proportion of pollutant emissions in region $i$ in year $t$ to represent the pollutant discharge of the manufacturing industrial transfer; $R E G D P_{i t}$ refers to GDP per capita in region $i$, reflecting wealth per capita; $A W A G E_{i t}$ refers to the average salary of staff, reflecting the state of regional labour cost; $U R B A N_{i t}$ refers to the proportion of the city or town population in relation to the total population of the region $i$, reflecting the regional urbanization level; $I S_{i t}$ denotes the proportion of tertiary industry output in GDP of the region $i$, reflecting the industrial structure level and standard; $I C A_{i t}$ denotes the proportion of R\&D expenditure in GDP, reflecting technical innovation ability; $D E A_{i t}$ refers to the overall utilisation rate of industrial solid waste, reflecting environmental 

governance efficiency; $E G I_{i t}$ refers to the amount of investment in environmental governance, reflecting the power of environmental governance; $G O V_{i t}$ denotes local fiscal expenditure, reflecting the government's degree of influence on pollution-intensive industrial transfer; $\varepsilon_{i t}$ is the residual error item; $\beta_{0}$ is the intercept; and the other $\beta$ values are regression coefficients of the various variables.

\subsection{Data collection and processing}

The data used in this study were geographic coordinate and socio-economic data collected to build the basic geographical database. Firstly, the geographic coordinate data of capitals used to calculate the regional gravity centre were obtained from Google Earth. Secondly, the pollutant discharge patterns are influenced by multiple socio-economic factors, and the data, such as GDP per capita, environmental investment, environmental regulation, and R\&D, were collected from the China Statistical Yearbook and 2005-2016 statistical yearbooks of Jiangsu, Zhejiang, Shanghai, Anhui, and Jiangxi. Manufacturing and other socio-economic data used were obtained from the China City Statistical Yearbook and statistical yearbooks of sample cities from 2005 to 2016. Meanwhile, the regional environmental data, such as industrial wastewater discharge, gaseous emissions, and solid waste emissions, came from the China Environmental Statistics Yearbook as well as the statistical yearbooks and Environmental Statistics Yearbook of the four provinces and one city. These officially published statistical yearbooks and other authoritative departments are viewed as the most reliable and available sources of data for studies on China's economy and industries (Wu et al., 2019). 
Finally, a geographical database of economic, technological, regulation, and environmental attributes of four provinces and one city was established. Additionally, based on the ArcGIS distance calculation tool, relevant analyses and plotting of the movement distance of the pollution centre were carried out to establish how locations evolved over time. After the data on economic development, such as GDP per capita, were adjusted for inflation, a pooled regression model was constructed to examine how economic, technological, and regulation factors affect the pollutant discharge pattern.

\section{Results}

\subsection{Changes in pollutant discharge pattern}

As shown in Fig. 3, the pollution gravity centre of the manufacturing industry had a tendency to move toward the west from 2005 to 2015 . The industrial wastewater centre continuously moved westward by $0.23^{\circ}$, showing a larger movement of $0.17^{\circ}$ from 2005 to 2010 . The industrial gaseous emissions centre also moved toward the west by $0.48^{\circ}$ and the industrial solid waste by $0.14^{\circ}$. The increase in industrial pollutant emissions was affected by the development of steel, heating power, electric power and other pollution-intensive industries in Jiangxi and Anhui. The overall movement of the industrial gaseous emissions centre was $0.08^{\circ}$ northward. The results indicate that the pollutant discharge pattern in the study area has undergone great changes.

In terms of the total amount of discharge (Fig. 4), the overall changes in the pollutant discharge pattern in the PYRD indicates transfer from the developed eastern area to the 
342 developing western area. Industrial $\mathrm{SO}_{2}$ emissions over the past decade showed a decreasing

343 trend, except in 2009 and 2011. The total amount of industrial wastewater emissions declined

344 by rates of $8.2 \%, 30.4 \%$, and $23.4 \%$ in Shanghai, Jiangsu, and Zhejiang, respectively, from

3452005 to 2015, whereas emissions in Jiangxi and Anhui increased by $12.4 \%$ and $41.5 \%$.

346 Fig. 5 shows that the intensity of pollutant discharge in the PYRD declined greatly from 2005

347 to 2015. The spatial patterns of industrial wastewater and gaseous emission intensity of

348 Shanghai and Zhejiang were the lowest, that of Jiangsu ranked in the middle, and those of

349 Anhui and Jiangxi were the highest. There was a trend of greater decline in the developed

350 eastern area than in the developing western area. However, the superimposition of pollution

351 occurring in each region and that caused by industrial transfer may impact the spatial pattern

352 of pollutant discharge.

\subsection{Response to industrial transfer}

354 Due to differences at the economic level, production factor endowment, and industrial

355 division in the PYRD, interregional competition and cooperation inevitably accompany the

356 gradient of industrial transfer. Along with the optimization and adjustment of the industrial

357 structure in the YRD represented by Shanghai, Jiangsu, and Zhejiang, more attention was

358 paid to developing emerging high-tech and high value-added industries. On the other hand,

359 the peripheral developing areas tended to undertake pollution-intensive and low value-added

360 sunset industries. Currently, traditional manufacturing industries tend to transfer from

361 developed cities, such as Shanghai, Jiangsu, and Zhejiang, to developing areas, such as Anhui 
362 and Jiangxi.

363 From 2005 to 2015, the centre of the pollution-intensive industries in the PYRD moved

364 toward the west by $0.73^{\circ}$. As a result, the proportion of pollution-intensive industries in

365 Shanghai, Jiangsu, and Zhejiang declined gradually by $7.08 \%, 5.05 \%$, and 2\%, respectively.

366 A similar trend was observed in the manufacturing industry in that the centre of pollutant

367 discharge moved westward, and that of industrial wastewater, gaseous emissions, and solid

368 waste shifted by $0.23^{\circ}, 0.48^{\circ}$, and $0.14^{\circ}$, respectively. The ratios of pollutant discharge

369 amounts of industrial wastewater, gaseous emissions, and solid waste in Jiangsu and Zhejiang

370 decreased respectively from $10.98 \%, 36.67 \%$, and $21.85 \%$ in 2005 to $7.16 \%, 35.92 \%$, and

$371 \quad 18.45 \%$ in 2015 . In contrast, the pollutant discharge amounts of Anhui and Jiangxi gradually

372 increased from $14.12 \%$ and $16.38 \%$ in 2005 to $21.33 \%$ and $17.14 \%$ in 2015 , respectively.

373 Therefore, developing areas, such as Anhui and Jiangxi, are becoming high-pollutant

374 discharge areas. However, the ratios of decreasing pollution-intensive industries are not

375 equivalent to those of pollutant discharge in Shanghai and Jiangsu, which indicates a time lag

376 in pollutant discharge. Otherwise, manufacturing industrial transfer and pollutant emissions

377 patterns were strongly spatially correlated.

\subsection{Driving mechanism of pollutant discharge pattern}

379 As stated earlier, regional economic difference, industrial structure adjustment, technological

380 progress, and government regulation are important socioeconomic factors influencing

381 pollutant discharge both jointly and individually. The effect degrees of these factors were 
382 evaluated with a pooled regression model, and Table 3 presents the regression results for the driving mechanism of the pollutant discharge pattern. The results of the stepwise regression

\subsubsection{Regional economic difference}

The differences in the economic development levels of the regions promoted the transfer of pollutant discharge from highly developed to poorly developed areas. There was a significant positive correlation between GDP per capita and changes in pollutant discharge pattern. In terms of the whole region, the GDP per capita increased by $1 \%$ and the proportion of pollutant discharge by $1.45 \%$. That is to say, although the PYRD actively adjusted its industrial structure, its dependence on pollution- and energy-intensive industries was still high. In areas with higher GDP per capita, such as Shanghai, Jiangsu, and Zhejiang, the proportion of pollutant discharge to that of the country decreased dramatically, but the total amount remained high. In the provinces with lower economic development, such as Anhui, the rates of economic and industrial development were high, and the amount of pollutant discharge increased. Moreover, the factor cost greatly influenced the pollutant discharge transfer, and 
403 the regression results are significant at a $\mathrm{P}$ value of 0.001 . Influenced by increasing labour costs in the YRD, labour-intensive industries gradually transferred from Shanghai to south Jiangsu, north Zhejiang, and then to north Jiangsu, Anhui, and Jiangxi, resulting in increased pollutant discharge in the transfer-in areas (Zhao and Jiang, 2013).

A significant positive correlation existed between the level of urbanization and pollution transfer. When urbanization level increased by $1 \%$, the proportion of pollutant discharge increased by $2.52 \%$. This indicates that the acceleration of urbanization may lead to the aggravation of environmental pollution from pollution intensive industries. Since 2005, urbanization in Anhui and Jiangxi has entered the stage of accelerated development. The urbanization rate has increased rapidly from $35.5 \%$ and $37 \%$ in 2005 to $50.5 \%$ and $51.6 \%$ in 2015. Large-scale population migration has increased the density of the urban population, the demand for various materials, and waste discharge in cities and towns. The industrial wastewater discharge and gas emissions in Anhui and Jiangxi increased from 1.17 and 1.1339 trillion $\mathrm{m}^{3}$ in 2005 to 1.48 and 4.6243 trillion $\mathrm{m}^{3}$ in 2015 , respectively. While Shanghai and Jiangsu are at the third level of high urbanisation and steady development, the improvement of residents' quality of life and changes in consumption have promoted environmental protection and gradually downscaled pollution. Overall, the higher level of economic development and factor cost in the transfer-out area encouraged the transfer of pollution-intensive industries to other areas. The lower factor cost in the transfer-in area and the urgency of prioritising economic development attracted the transfer of pollution-intensive industries, thus promoting inter-regional transfer of pollutant discharge. 


\subsubsection{Industrial structure adjustment}

Industrial restructuring and upgrading are important measures to reduce pollutant emissions and improve environmental quality. The simulation results show that the industrial structure significantly impacted the evolution of manufacturing industries in the PYRD, and the regression coefficient was negative. The proportion of tertiary industries in GDP increased by $1 \%$, whereas pollutant emissions decreased by $0.24 \%$. This shows that the optimization and upgrading of industrial structure in Shanghai, Jiangsu, and Zhejiang restrained the total amount and intensity of pollutant emissions and promoted the transfer of pollutant emissions to developing areas, such as Anhui and Jiangxi.

The adjustment and upgrading of industrial structure greatly reduced pollutant emissions through the improvement of production technology, resource utilization efficiency, and pollution prevention and control capability. Furthermore, it reduced environmental pollution by eliminating some pollution-intensive and low value-added industries and increased some emerging high-tech and high value-added industries. This was the impetus for promoting the transfer of pollution-intensive industries to western regions. Along with boosting the integration process in the PYRD, Anhui and Jiangxi now lead industrial transfer from Shanghai, Jiangsu, and Zhejiang. Some pollution-intensive industries in Jiangsu, Zhejiang, and Shanghai have gradually transferred to Anhui and Jiangxi, driving the pollutant discharge 


\subsubsection{Technological progress}

Technological progress is an important approach to driving pollutant discharge transfer. Technological innovation capability is negatively correlated with changes in pollutant emission pattern, which indicates that the improvement of innovation capability is beneficial for reducing pollutant emissions. However, its effect was only 0.27 , indicating that technological innovation capability has less influence on pollutant emission transfer than other factors do. Shanghai, Jiangsu, and Zhejiang are among the densest areas in terms of scientific research institutions, scientific and technological talent, and high-tech industries in China. There are also more investments in scientific technology than in the other regions.

Generally, industries with high R\&D have higher added-value and tend to offset part of the cost growth caused by increasing labour. Therefore, there is little possibility for industrial transfer, and industries with high $R \& D$ intensiveness are still concentrated in the core of the PYRD. Because of technological progress, energy efficiency improvement, and low pollution from high-tech industries, pollutant discharge in the PYRD gradually decreased.

Similarly, the efficiency of environmental governance is negatively correlated with changes in pollutant discharge pattern and the manufacturing industry, that is, the higher the efficiency of environmental governance was, the lower the total amount and intensity of pollutant discharge was. Highly efficient environmental governance in Shanghai, Jiangsu, and Zhejiang caused the decreased pollutant discharge in the area to some extent. The improvement in technological level and innovation ability was not only the resistance to pollution-intensive industries remaining in the eastern region but also the impetus to promote the transfer of 
464 pollution-intensive industries towards the western region. Overall, the direction of pollution

465 transfer due to manufacturing industrial transfer is the direction of decreasing technological

466 innovation capability.

\section{4.3.4. Government regulation}

468 Government regulation is an important factor influencing the changes in pollutant discharge

469 pattern due to manufacturing industrial transfer. The intensity of environmental governance is negatively correlated with the transfer of pollutant discharge, but the correlation coefficient was only 0.045 . Investment in environmental protection increased, and the intensity of

472 industrial pollutant control increased in the core of the PYRD, which plays an important role

473 in controlling environmental pollution. In western areas, such as Anhui and Jiangxi, the 474 prevention of and control over industrial pollution were weak, and the environmental 475 protection infrastructure was insufficient, which was not conducive to the control of industrial 476 pollution and promoted the transfer of pollutant discharge towards Anhui and Jiangxi to some extent.

As an important means for the government to control the layout of pollution-intensive industries, local fiscal expenditure reflects the extent of the government's influence on

480 pollutant discharge transfer. Empirical evidence shows that for every $1 \%$ increase in local

481 fiscal expenditure, the proportion of pollutant discharge decreases by $0.37 \%$. Developed cities 482 in Shanghai, Jiangsu, and Zhejiang are increasingly stringent on industries, and constantly improving environmental policy is the driving force behind the transfer of pollution-intensive 
484 industries from the eastern part of the country. While Anhui and Jiangxi, in the context of the

485 rising central economy, is developing rapidly at lower costs to drive the economy, their relatively loose industrial policy is a driving force for attracting the transfer of peripheral industries. This inevitably leads to the transfer of pollution-intensive industries and increased pollutant discharge. Consequently, western areas with weaker environmental regulation have become the primary region for the transfer of pollutant discharge.

\section{Discussion}

Improvements in the economy of the PYRD still largely depend on pollution- and energy-intensive industries. Therefore, as found in this study, the manufacturing industry has transferred for coordinating regional economic development, accompanied by the transfer of pollution-intensive industries, and this finally influenced the changes in pollutant discharge pattern of the manufacturing industry. This conclusion is consistent with previous studies. For example, Yin et al. (2016) confirmed that the transfer of pollution-intensive industries promotes economic development while also causing pollution transfer and diffusion. Wang et al. (2014) and Zhao et al. (2014) identified that environmental pollution had a similar spatial pattern to that of the geographic industrial concentration, that is, high in eastern China and low in the west. Meanwhile, with evaluating the shifting of pollution gravity centre, this study will contribute to the literature with a more quantitative result. Furthermore, the findings also indicated a delayed response between the movement of industry and the changes in pollutant emissions, which demonstrated the opinion of delayed response pointed out by Gai et al. (2013), making it not only true in theory but also in practice. This provided a macro-analysis 
505 of the pollutant discharge pattern in response to industrial transfer, which expands and

506 deepens understanding of the relationship between these processes.

507 In PYRD, the changes in pollutant discharge patterns caused by manufacturing industry are

508 currently influenced by factors including economic development, industrial structure, and

509 environmental governance. These findings verified the results of the early-stage qualitative

510 analysis by Zhao et al. (2014). Although the conclusions of the studies are consistent, it

511 should be noticed that the influencing factors and degree of action in different regions at

512 different stages of development usually differed. Zhang et al. (2011) suggested the industrial

513 structure has more obvious effect on waste pollution. And our results have further interpreted

514 how different factors worked positively or negatively in varying degrees. This verified and

515 further explained the findings from previous study that the effects of different environmental

516 regulations, as well as the changes in regional and industrial characteristics, on the

517 distribution of pollution-intensive industry are complicated (Zhou et al., 2017). Besides the

518 general factors of economic development, industrial upgrading, technological progress, and

519 government regulation, natural endowment, population migration and other factors can also

520 make great impact. For example, Heras-Saizarbitoria et al. (2015) pointed that the effects of

521 regional factor endowments probably surpassed that of policies, such as environmental

522 regulations, although regulations may have a greater impact at the micro industrial sector

523 levels. This indicates the demand of a more comprehensive driving mechanism research.

524 Moreover, considering the findings above and the situation that some local governments in

525 developing regions still pursue industrial developments at the expense of the environment 
with the deepening of fiscal decentralization (Dong et al., 2015), here we recommended properly designed environmental regulations to stimulate technological innovation and cleaner production, as well as contribute to industrial upgrading.

In this study, the modified STIRPAT random regression model was constructed with the analysis framework of the push-pull theory, and was combined with GIS-based spatial analysis methods to study the driving mechanism of pollutant discharge pattern change due to industrial transfer. Although the methods are by no means perfect, they do help to target our subjects more precisely and ensured the robustness of the research. However, in this study, only economic development, industrial structure, technical effect, and policy were considered, as these factors are known to influence the spatial patterns of pollutant discharge in the manufacturing industry. This inevitably overlooked some factors that are important to some regions. And the changes in industrial and pollutant transfer within the PYRD are complex, because Shanghai, Zhejiang, Jiangsu, Jiangxi, and Anhui are considered to be a single unit, the intra-provincial transfers and the specific industries transfer were not considered. Therefore more detailed investigations into pollutant transfer in sub-regions and different pollution-intensive industries are still required.

\section{Conclusions}

A large number of literatures have investigated the redistribution of pollution-intensive industry and the accompanying change in pollution (Dean et al., 2009; Wang et al., 2019). Nevertheless, it is still unclear how the pollutant discharge pattern responds to industrial transfer and its driving mechanism. To fill this research gap, we focus on the changes in 
547 pollutant discharge pattern and its spatio-temporal response to industrial transfer, with

548 particular attention to regional driving forces.

549 We find that the pollutant discharge pattern of the manufacturing industry in China has 550 changed and has undergone a process of geographical transferal from the eastern developed 551 area to the western developing area. Between 2005 and 2015, rates of total pollutant discharge

552 declined to different extents in Shanghai, Jiangsu, and Zhejiang, whereas they showed an 553 increasing trend in Jiangsu and Anhui. During the same period, the pollutant discharge 554 intensity declined sharply in Shanghai, Jiangsu, and Zhejiang but slightly decreased in Anhui 555 and Jiangxi. The pollution gravity centre generally moved westward.

556 As expected, the pollutant discharge pattern of the manufacturing industry was influenced by 557 multiple factors, including regional economic differences, industrial structure adjustment, 558 technical effect, and government policy. Differences in interregional economic development 559 level drove the pollutant discharge transfer from more to less developed regions. Cheaper 560 factor costs and loose macro-environmental policies in developing areas attracted 561 pollution-intensive industrial transfer from developed areas. Moreover, rapid technical 562 advances and industrial structure optimization and adjustment, amongst others, were a 563 resistance to the development of pollution-intensive industries in developed areas. It was also

564 an impetus for driving pollution-intensive industries to transfer towards developing areas.

565 In addition, the pollutant discharge pattern of the manufacturing industry showed certain 566 spatial correlations with industrial transfer and indicated a time lag. While pollution-intensive 
manufacturing industries were transferred to developing areas, highly polluted areas showed the same expansion trend. For developing areas, it is important to avoid a pollution build-up

569 resulting from the transfer of pollution-intensive manufacturing industries from developed developed in environmentally sensitive zones providing important ecosystem functions.

\section{Acknowledgments} and the National Natural Science Foundation of China (No. 71573250).

\section{$575 \quad$ References}

576 Akbostanci E., Tunc G., Turut-Asik S., 2007. Pollution Haven Hypothesis and the Role of Dirty

577 Industries in Turkey 'Exports. Environ. Dev. Econ., 12, 297-322.

578 Candau, F., Dienesch, E., 2017. Pollution haven and corruption paradise. J. Environ. Econ. Manag. 85, $579 \quad 171-192$.

580 Cole, M.A., Elliott, R.J.R., 2003. Determining the trade-environment composition effect: The role of

581 capital, labor and environmental regulations. J. Environ. Econ. Manag. 46(3), 363-383.

582 Dam, L., Scholtens, B., 2008. Environmental regulation and MNEs location: Do CSR matter? Ecol.

583 Econ. 67(1), 55-65.

584 Dean, J.M., Lovely, M.E., Wang, H., 2009. Are foreign investors attracted to weak environmental 
586 Ding, H.-F., Li, P.-Y., 2009. The variation contrastive analysis of economy gravity centre and regional pollution gravity center of China: 1986-2006. Econ. Geogr. 29, 1629-1633.

Dong, L., Dong, H., Fujita, T., Geng, Y., Fujii, M., 2015. Cost-effectiveness analysis of China's sulfur Prod. 90, 345-359.

Ederington, J., Levinson, A., Minier, J., 2005. Footloose and pollution-free. Rev. Econ. Stat. 87, 92-99.

Dong, B., Gong, J., Zhao, X., 2012. FDI and environmental regulation: Pollution haven or a race to the top? J. Regul. Econ. 41(2), 216-237.

Dou, J. M., Shen, Y. B., 2014. On the Influence of the Industrial Transfer on the Environment in the Central Region of China. China Popu. Res. and Environ. 24(11), 96-102.

Fan, J.Y., 2004. Yangtze River Delta region integration, regional specialization and manufacturing spatial transformation. Manag. World. (11), 77-85.

Gai, M., Hu, H.A., Ke, L.N., 2013. Decoupling analysis between economic development and resources and environment of the Yangtze River Delta. J. Nat. Resour. 28(2), 185-198.

Gao, J.X., Fan, X.S., 2009. Pollution footprint contrastive analysis on industrial import and export in

China. China Environ. Sci. 29(1), 106-112.

Grether, J.M., Melo, J.D., 2003. Globalization and dirty industries: Do pollution havens matter? NBER Working Paper Series 9776, 1-48.

Guo, J., Zhang, Z., Meng, L., 2012. China's provincial $\mathrm{CO}_{2}$ emissions embodied in international and 
605 interprovincial trade. Energ. Policy 42, 486-497.

606 He, C. F., Wang, J. S., 2012. Regional and sectoral differences in the spatial restructuring of Chinese

607 manufacturing industries in the post-WTO period. GeoJournal, 77(3):361-381.

608 Heras-Saizarbitoria, I., Arana, G., Boiral, O., 2015. Exploring the dissemination of environmental

609 certifications in high and low polluting industries. J. Clean. Prod. 89, 50-58.

610 Hoekstra, R., Van der Bergh, J.C.J.M., 2006. Constructing physical input-output tables for

611 environmental modelling and accounting: Framework and illustrations. Ecol. Econ. 59(3), 375-393.

612 Hou, W.L., Fang, L., Liu, S., 2013. Do pollution havens exist in China? An empirical research on

613 environmental regulation and transfer of pollution intensive industries. Econ. Rev. (4), 65-72.

614 Huang, J.S., Feng, Z.X., 2006. The variation track and contrastive analysis on the social economic

615 gravity centre and environmental pollution gravity centre in Shaanxi province. Hum. Geogr. 21(4), $616 \quad 117-122$

617 Jungbluth, N., Stucki, M., Leuenberger, M., 2011. Environmental impacts of Swiss consumption and 618 production: A combination of input-output analysis with life cycle assessment. Federal Office for the 619 Environment FOEN, Bern.

Kivyiro, P., Arminen, H., 2014. Carbon dioxide emissions, energy consumption, economic growth, and

621 foreign direct investment: causality analysis for SubSaharan Africa. Energy 74, 595-606.

622 Lehmijoki, U., Rovenskaya, E., 2010. Air pollution in Europe 2020: The gravity model and EKC 623 decomposition. Helsinki Center of Economic Research Discussion Paper 292, 1-21. 
624 Li, P., Cao, Y., 2013. Spatial and temporal changes of industrial carbon emissions under regional industrial transfer: The case of Pan-Yangtze River Delta. Adv. Earth Sci. 28(8), 939-947.

626

Liang, S., Zhang, T., Wang, Y., Xiaoping, J., 2012. Sustainable urban materials management for air pollutants mitigation based on urban physical input-output model. Energy 42(1), 387-392.

Liddle B, 2013. Population, affluence, and environmental impact across development: Evidence from panel cointegration modeling. Environ. Model Softw. 40, 255-266.

Liu, Q.L., Wang, Q., Li, P., 2012. Regional distribution changes of pollution-intensive industries in China. Ecol. Econ. (1), 107-112.

Lu, D.D., Fan, J., 2012. The rise and effects of regional sustainable development studies in China. Bull. Chin. Acad. Sci. 27(3), 290-300, 319.

Mielnik, O., Goldemberg, J., 2002. Foreign direct investment and decoupling between energy and gross domestic product in developing countries. J. Energy Policy. 30(2), 87-89.

Millimet, D.L., Roy, J., 2015. Empirical tests of the pollution haven hypothesis when environmental regulation is endogenous. J. Appl. Econ. 31, 652-677.

Moussiopoulos, N., Helmis, C.G., Flocas, H.A., Louka, P., Assimakopoulos, V.D., Naneris, C., Sahm, P., 2004. A modelling method for estimating trans-boundary air pollution in southeastern Europe. Environ. Modell. Softw. 19(6): 549-558.

Muradian, R., O’Connor, M., Martinez-Alier, J., 2002. Embodied pollution in trade: Estimating the 'environmental load displacement' of industrialised countries. Ecol. Econ. 41(1), 51-67. 
643 Qiu, F.D., Jiang, T., Zhang, C.M., Shan, Y.B., 2013. Spatial relocation and mechanism of

644 pollution-intensive industries in Jiangsu province. Sci. Geogr. Sinica 33(7), 789-796.

645 Sapkota, P., Bastola, U., 2017. Foreign direct investment, income, and environmental pollution in 646 developing countries: panel data analysis of Latin America. Energy Econ. 64, 206-212.

647 Shahbaz, M., Nasreen, S., Abbas, F., Anis, O., 2015. Does foreign direct investment impede 648 environmental quality in high-, middle- and low-income countries? Energy Econ. 51, 275-287.

649 Shen, J., Xiang, C., Liu, Y.Y., 2012. The mechanism of pollution intensive industry relocation in 650 Guangdong province, 2000-2009. Geogr. Res. 31(2), 357-368.

651 Shi, A., 2003. The impact of population pressure on global carbon dioxide emissions, 1975-1996: evidence from pooled cross-country data. Ecol. Econ., 44(1), 24-42. Shi, G.M., Wang, J.N., Bi, J., Zhou, Q., 2012. Decomposing Chinese industrial $\mathrm{SO}_{2}$ emission change index. China Environ. Sci. 32(1), 56-61.

Silajdzic, S., Mehic, E., 2017. The Impact of Environmental Taxes on Competitive Performance of Pollution-intensive Industries Among Transition Economies: Evidence from Panel Analysis, Financial dynamic system model based on Push-pull theory. Rev. Econ. Res. 47, 65-69,111. centers and its spatial correlation in Pan Yangtze River Delta. China Popu. Res. and Environ. 24(3), 
$662 \quad 55-59$.

663 Wang, L.M., He, K.L., 2008. Analysis of spatial variations in environmental impact based on the

664 STIRPAT model-A case study of energy consumption. Acta Scien. Circum. (05), 1032-1037.

665 Wang, Z., Chen, S.T., Cui, C., Liu, Q.L., Deng, L.C., 2019. Industry relocation or emission relocation?

666 Visualizing and decomposing the dislocation between China's economy and carbon emissions. J. Clean.

667 Prod. 208, 1109-1119.

668 Wu, J.W., Wei, Y.H., Chen, W., Yuan, F., 2019. Environmental regulations and redistribution of 669 polluting industries in transitional China: Understanding regional and industrial differences. J. Clean. 670 Prod. 206, 142-155.

671 Xu, H.Z., Yin, H.C., Shi, S.Q., 2013. Analysis of Influential Factors of Withdrawing from Rural 672 Residential Land and Migrant Workers' Urban-Rural Migration under the Perspective of 673 Intergenerational Differences: An Empirical Study on the Basis of Push-Pull Theory. China Popu. Res. 674 and Environ. 23(8),75-80.

675 Xu, J., Zhang, M., Zhou, M., Li, H., 2017. An empirical study on the dynamic effect of regional 676 industrial carbon transfer in China. Ecol. Indicat. 73, 1-10.

677 Xu, Y., Zhang, T., 2009. A new approach to modelling waste in physical input-output analysis. Ecol. 678 Econ. 68(10), 2475-2478.

679 Yang, C.H., Tseng, Y.H., Chen, C.P., 2012. Environmental regulations, induced R\&D, and productivity:

680 evidence from Taiwan's manufacturing industries. Resour. Energy Econ. 34 (4), 514-532. 
681 Ye, P.W., Zhou, M., 2008. The poverty of migrant workers: an analysis framework based on Todaro 682 Model. Manag. World. (9), 174-176.

683 Yin J.H., Zheng M.Z., Li X., 2016. Interregional transfer of polluting industries: a consumption 684 responsibility perspective. J. Clean. Prod. 112, 4318-432.

685 York, R., Rosa, E.A., Dietz, T., 2003. STIRPAT, IPAT and ImPACT: analytic tools for unpacking the 686 driving forces of environmental impacts. Ecol. Econ. 46 (3), 351-365.

687 688 21(S1), 275-279.

694 Zhang, X.J., Zhao, K., Sun, P., 2015. Impacts of basic environmental public service provision on 695 environmental quality in China - based on STIRPAT model. J. Arid Land Res. and Environ. 29(11), $696 \quad 43-48$.

697 Zhang, Y., Zhang, J., Yang, Z., Li, J., 2012. Analysis of the distribution and evolution of energy supply 698 and demand centers of gravity in China. Energy Pol. 49,695-706. 
700 Social Sciences Press, Beijing.

701 Zhao, H.X., 2009. Economic development, institutional arrangement and environmental effects. China

702 Environmental Science Press, Beijing.

703 Zhao, H.X., Jiang, X.W., 2013. Evolution of economic and industrial pollution gravity centres and the

704 decoupling mechanism in Yangtze River Delta. China Environ. Sci. 33(10), 1911-1919.

705 Zhao, H.X., Jiang, X.W., Cui, J.X., 2014. Shifting path of industrial pollution gravity centres and its

706 driving mechanism in Pan-Yangtze River Delta. Environm. Sci. 35(11), 4387-4394.

707 Zhao, X.F., Huang, X.J., Zhang, X.Y., Zhu, D.M., Lai, L., Zhong, T.Y., 2009. Application of spatial

708 autocorrelation analysis to the $\mathrm{COD}, \mathrm{SO}_{2}$ and TSP emission in Jiangsu Province. Environm. Sci. 30(6),

$709 \quad 1580-1587$.

710 Zhao, X., Zhao, Y., Zeng, S., Zhang, S., 2015. Corporate behaviour and competitiveness: impact of

711 environmental regulation on Chinese firms. J. Clean. Prod. 86, 311-322.

712 Zheng, D., Shi, M., 2017. Multiple environmental policies and pollution haven hypothesis: evidence

713 from China's polluting industries. J. Clean. Prod. 141, 295-304.

714 Zhou, Y., Zhu, S., He, C., 2017. How do environmental regulations affect industrial dynamics?

715 Evidence from China's pollution-intensive industries. Habitat Int. 60, 10-18.

716 Zhu, D.C., Lu, L., Jin, X.L., 2010. Analysis of spatial pattern and economic effects: An empirical study

717 of FDI in Pan-Yangtze Delta. Sci. Geogr. Sinica. 30(2), 184-189.

718 Zou, H., Duan, X.J., Zhao, H.X., Wang, L., 2016. Spatial evolution of pollution-intensive industries 
1719 and its effects on pollution emissions in Yangtze River Delta. J. Grad. Univ. Chin. Acad. Sci. 33(05), 703-710. 

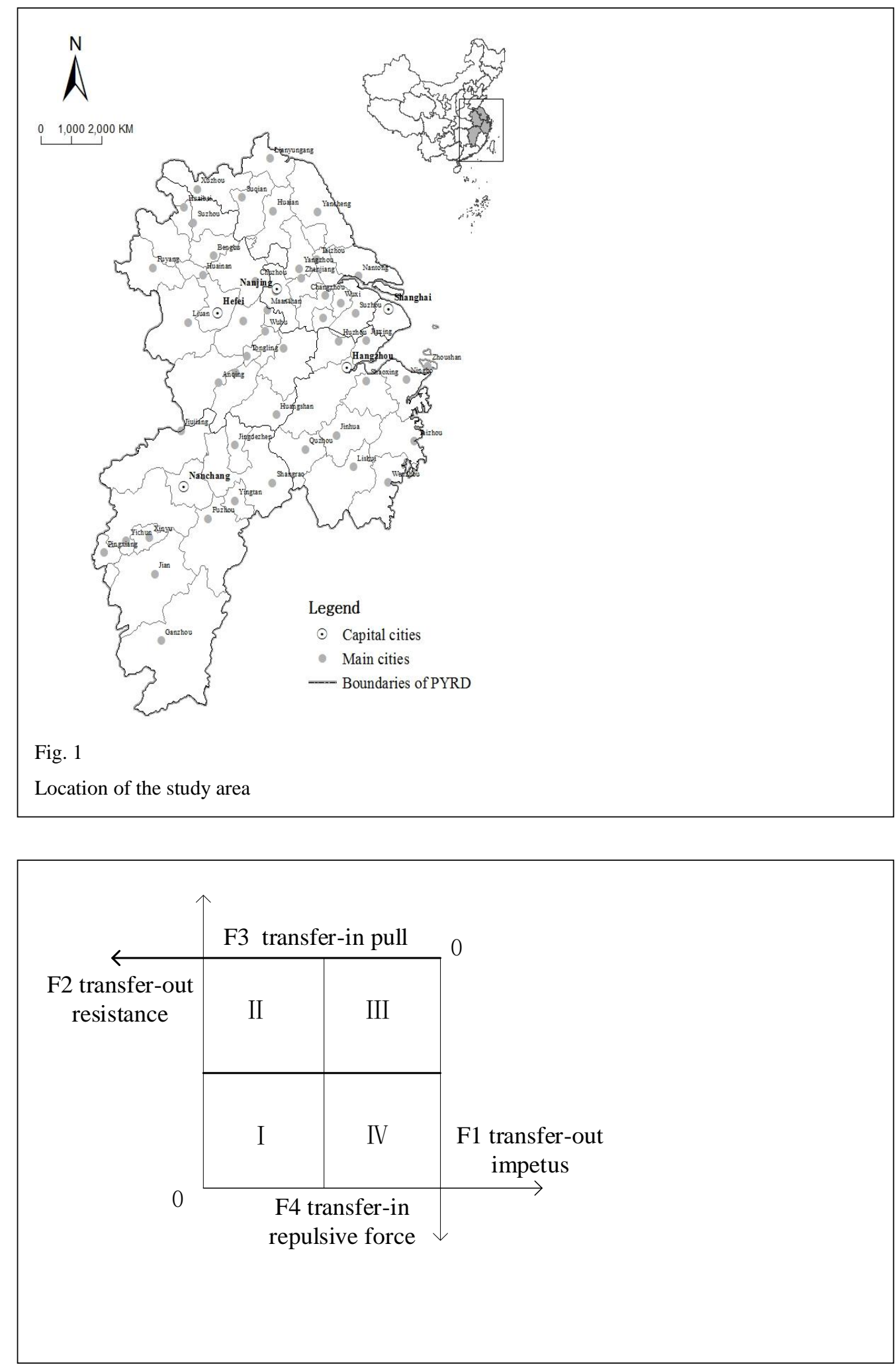

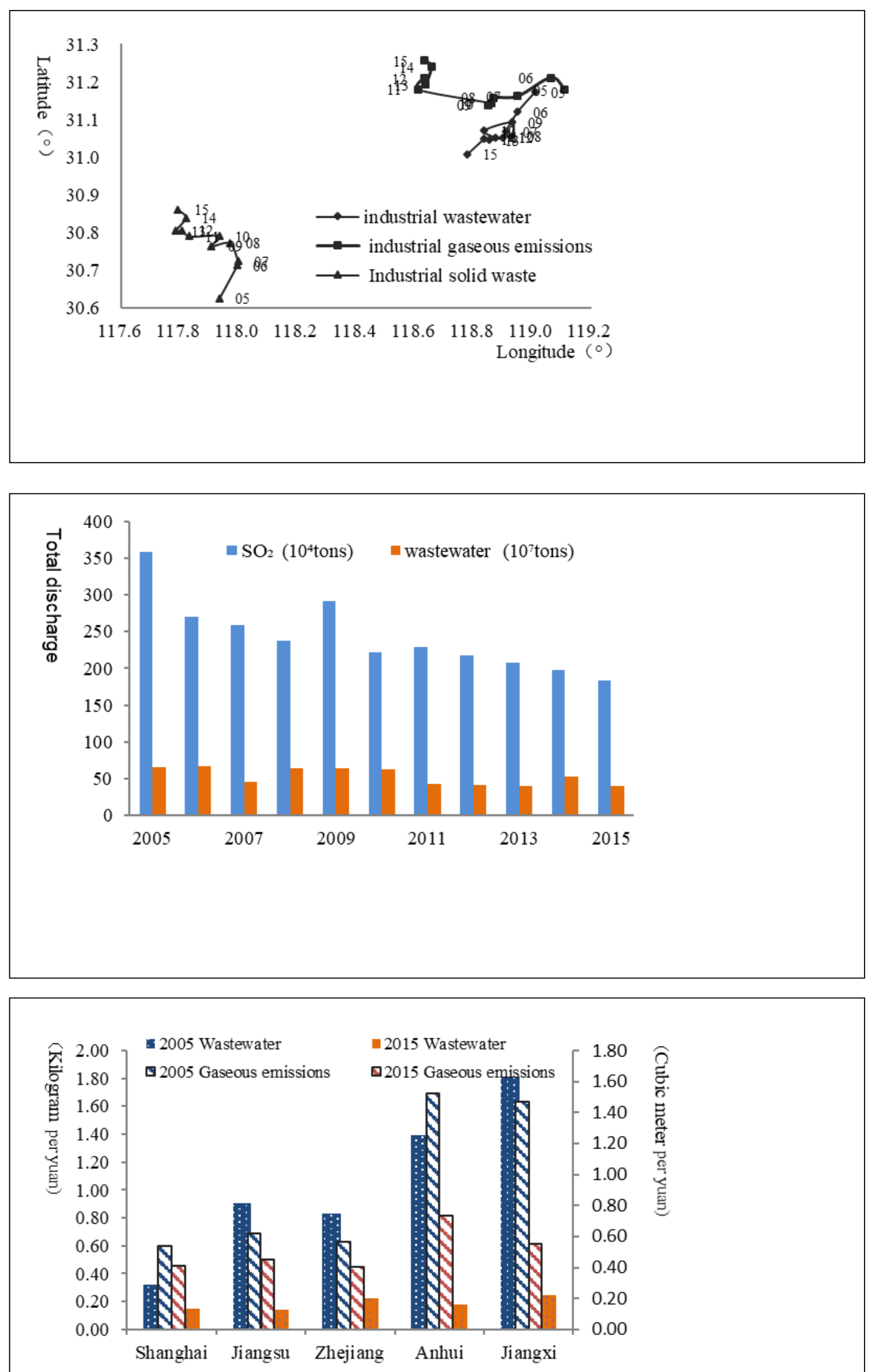
Table 1.

List of pollution-intensive industries.

\begin{tabular}{cc}
\hline Number & Name \\
\hline 1 & farm and side-line food processing \\
2 & food manufacturing \\
3 & textile \\
4 & leather, fur, and feather and their products shoe making \\
5 & papermaking and paper products \\
6 & chemical materials and chemical products manufacture \\
7 & ferrous metal smelting and rolling processing \\
8 & oil processing, coking, and nuclear fuel processing \\
9 & non-metallic mineral products \\
10 & non-ferrous metal metallurgy and rolling processing \\
\hline
\end{tabular}

Table 2 .

Definition of indicators.

\begin{tabular}{|c|c|c|c|c|}
\hline Name & Index & Code & Remark & $\begin{array}{l}\text { Possible } \\
\text { Strength }\end{array}$ \\
\hline \multirow{3}{*}{$\begin{array}{c}\text { Economic } \\
\text { development }\end{array}$} & $\begin{array}{l}\text { Wealth per } \\
\text { capita }\end{array}$ & REGDP & Per capita GDP (yuan) & Positive \\
\hline & Factor cost & AWAGE & Average salary of staff (yuan) & Negative \\
\hline & $\begin{array}{l}\text { Urbanisation } \\
\text { rate }\end{array}$ & URBAN & $\begin{array}{l}\text { Proportion of city and town population in total } \\
\text { population }(\%)\end{array}$ & Positive \\
\hline $\begin{array}{l}\text { Industrial } \\
\text { structure }\end{array}$ & $\begin{array}{l}\text { Ratio of } \\
\text { tertiary } \\
\text { industry }\end{array}$ & IS & Proportion of tertiary industry output in GDP (\%) & Negative \\
\hline \multirow{2}{*}{$\begin{array}{c}\text { Technical } \\
\text { effect }\end{array}$} & $\begin{array}{l}\text { Innovative } \\
\text { ability }\end{array}$ & ICA & Proportion of R\&D expenditure in GDP (\%) & Negative \\
\hline & $\begin{array}{c}\text { Environmental } \\
\text { governance } \\
\text { efficiency }\end{array}$ & DEA & Overall utilisation rate of industrial solid waste $(\%)$ & Negative \\
\hline \multirow{2}{*}{$\begin{array}{l}\text { Government } \\
\text { policy }\end{array}$} & $\begin{array}{c}\text { Environmental } \\
\text { governance } \\
\text { power }\end{array}$ & EGI & $\begin{array}{c}\text { Proportion of environmental governance investment } \\
\text { volume in GDP }(\%)\end{array}$ & Negative \\
\hline & $\begin{array}{l}\text { Local fiscal } \\
\text { expenditure }\end{array}$ & GOV & local fiscal expenditure (billion) & Negative \\
\hline
\end{tabular}


Table 3.

Model results.

\begin{tabular}{ccccc}
\hline Variable & Estimate & Std. Error & $\mathrm{t}$ value & $\operatorname{Pr}(>|\mathrm{t}|)$ \\
\hline Intercept & 9.54169 & 0.67496 & 14.137 & $<2 \times 10^{-16 * * *}$ \\
REGDP & 1.45004 & 0.19252 & 7.532 & $2.95 \times 10^{-9 * * *}$ \\
AWAGE & -1.65446 & 0.14239 & -11.619 & $1.5 \times 10^{-14 * * *}$ \\
URBAN & 2.51815 & 0.4296 & 5.862 & $6.81 \times 10^{-7} * * *$ \\
IS & -0.23951 & 0.27469 & -0.872 & $0.038831^{*}$ \\
ICA & -0.27531 & 0.09669 & -2.848 & $0.00686^{* * *}$ \\
DEA & -0.44773 & 0.08597 & -5.208 & $5.73 \times 10^{-6 * * *}$ \\
EGI & -0.04532 & 0.07747 & -0.585 & 0.56178 \\
GOV & -0.36696 & 0.14172 & -2.589 & $0.01325^{*}$ \\
\hline
\end{tabular}

Notes: Estimate shows estimation regression coefficient; Std. Error shows standard error; t value shows statistical magnitude of $\mathrm{t} ; \operatorname{Pr}(>|\mathrm{t}|)$ shows value of $\mathrm{P}$; Intercept shows intercept. $* * *, * *$ and $*$ enote significance at $0.001,0.01$, and 0.05 , respectively. 
Dear editor,

I wish to submit an original article for publication in Journal of cleaner production, titled "Change, mechanism, and response of pollutant discharge pattern resulting from manufacturing industrial transfer: A case study of the Pan-Yangtze River Delta, China." The paper was coauthored by Yan Liu, Sarah Lindley, Fei Meng and Mingjie Niu.

This study expands and deepens our understanding of the relationship between economic development and environmental pollution. This study establishes that the pollutant discharge pattern of the manufacturing industry in the study area has changed, having undergone transfer from the developed area in the east to the developing area in the west, and this aspect is influenced by several factors such as economic differences, industrial structure adjustment, technological effect and government policy. We believe that our study makes a significant contribution to the literature because it shows that industrial transfer in China leads to a spatial response of the environment and can advance understanding of restructuring processes and mechanisms of change in pollutant discharge pattern resulting from industrial transfer at finer geographical scales.

Further, we believe that this paper will be of interest to the readership of your journal because it may provide a new perspective for discussing the elements which affect the pollutant discharge pattern of the manufacturing industry in Chinese most developed area.

This manuscript has not been published or presented elsewhere in part or in entirety. We have read and understood your journal's policies, and we believe that neither the manuscript nor the study violates any of these. There are no conflicts of interest to declare.

Please note the column fitting requirements for each figure: Figure 1 - single column, figure 2 1.5 column, figure 3- 1.5 column, figure 4 - 2 column, and figure 5 - 1.5 column.

Thank you for your consideration. I look forward to hearing from you.

Sincerely,

Haixia Zhao

Key Laboratory of Watershed Geographic Sciences, Nanjing Institute of Geography and Limnology, Chinese Academy of Sciences

No.73 East Beijing Road, Nanjing, 210008, China

+86 (0)2586882132

+86 (0)2586882136

zhhx0183@163.com 